\title{
MICROSTRUCTURE, MECHANICAL PROPERTIES AND CORROSION BEHAVIOUR OF IRON - MANGANESE PM MATERIALS PRESSED AND SINTERED ONCE AND TWICE
}

\author{
M. Kupková, M. Hrubovčáková, M. Kabátová, M. Kupka
}

\begin{abstract}
Elemental iron and manganese powders were blended to form mixtures containing 25, 30 and 35wt.\% Mn. Mixtures were compressed into prismatic bars and sintered. Some of the bars were repressed and resintered. Compared to a bar pressed and sintered once, the bar pressed and sintered twice possessed a higher relative density, a higher bending stiffness, and a grid microindentation data set with a lower variance. Bars were immersed in Hank's solution for eight weeks. After this procedure, the bending stiffness were found reduced for all bars except for those pressed, sintered and only repressed, the bending stiffness of which remained unchanged. The repressing has most likely closed up throats connecting the clusters of pores with the free surface of a bar, reducing thus a surface area exposed to a corrosive attack. The resintering has opened up those throats, the electrolyte could fill accessible pores and corrosion weakened the near-surface material, reducing thus a bar's bending stiffness.
\end{abstract}

Keywords: corrosion, immersion test, Fe-Mn, pressed and sintered materials, bending stiffness

\section{INTRODUCTION}

During the healing process and remodeling of various injured tissues, the aid of implants, e.g. coronary stents, fixtures for fractured bones, scaffolds for tissue engineering, is needed only temporarily. After the mission is fulfilled, the implants cannot provide any beneficial effect. Currently-used corrosion resistant implants are either removed from the body by the second surgery, or they are left in the body with the risk that the presence of a foreign object can trigger late complications.

The idea to replace permanent implants with biodegradable ones, which can fulfill their mission in the body for a required period and then quietly dissolve away, has attracted great attention in the biomaterials community. What remains is to seek metallic materials which can do the job well.

Alloys based on $\mathrm{Fe}$ and $\mathrm{Mn}$ seem to be promising candidates for an application in degradable temporary implants such as cardiovascular stents and bone fixation devices $[1,2,3]$. While implanted in the human body, biomaterials are exposed to a harsh physiological environment. In attempts to modify the corrosion rate in a such environment to match the rate at which the damaged tissue heals and regenerates, additional alloying (Fe-Mn-Pd, Fe-Mn-Si,..) or various technological treatments were tried [4,5,6,7].

Miriam Kupková, Monika Hrubovčáková, Margita Kabátová: Institute of Materials Research of SAS, Košice, Slovakia

Martin Kupka: Institute of Experimental Physics of SAS, Košice, Slovakia 
The degradation of implants leads to a decrease in their mechanical properties. A small effort was put into investigation of deterioration of mechanical properties with proceeding corrosion, thought it is important to maintain the implant's mechanical integrity and scaffolding ability until the newly developed tissue is strong enough to resist the forces itself.

Some data concerning mechanical properties, corrosion performance and changes in properties with corrosion of some sintered Fe-Mn materials were published in papers $[8,9,10]$. This contribution seeks to provide similar data for the same materials after they were densified by repressing and resintering.

The article also compares microstructures, mechanical properties, and the effect of exposure to Hank's solution on the bending stiffness of bars from Fe-Mn alloys pressed and sintered once and twice.

\section{MATERIALS AND METHODS}

Elemental Fe and Mn powders were used as raw materials, namely a wateratomized iron powder produced by Höganäs (ASC 100.29 grade) and a manganese powder produced by Alfa Aesar GmbH \& Co KG (APS $<10$ micron, 99.6\%). Iron and manganese powders were blended to obtain mixtures containing 25, 30 and $35 \mathrm{wt} . \%$ of $\mathrm{Mn}$ powder. Mixtures were die compacted at $600 \mathrm{MPa}$ into prismatic bars $(20 \mathrm{~mm} \times 4 \mathrm{~mm} \times 4 \mathrm{~mm})$. Compacts were heated at a rate of $10^{\circ} \mathrm{C} / \mathrm{min}$ to the temperature of $1120^{\circ} \mathrm{C}$, held at this temperature for 60 minutes and then cooled at a rate of $10^{\circ} \mathrm{C} / \mathrm{min}$ to the room temperature. The sintering atmosphere consisted of $10 \% \mathrm{H}_{2}-90 \% \mathrm{~N}_{2}$, its purity was 5.0 , its dew point was $-59^{\circ} \mathrm{C}$. The sintering atmosphere flowed at a rate of $4 \mathrm{l} / \mathrm{min}$.

To reduce the sample's porosity and to increase the homogeneity of distribution of alloying elements, some of already sintered samples were repressed and sintered once more. The direction of pressing was perpendicular to that of the first pressing.

Sintered bars were polished with $0.1 \mu \mathrm{m}$ diamond paste. Dimensions, weight and theoretical density of each bar were determined and the porosity of each bar was subsequently evaluated.

The microstructure of specimens was examined by optical microscope (OLYMPUS GX71, Japan) and scanning electron microscope coupled with the energy dispersive spectrometer (JEOL JSM-7000F, Japan with EDX INCA).

The Vickers microhardness (HV 0.01) of various regions of samples has been measured using the microhardness tester LECO LM-700AT. For each sample, 300 microindents were performed at different points of sample with the indentation loading of $\log (0.1 \mathrm{~N})$.

The modulus of elasticity was determined by means of equipment BUZZOSONIC 5.9.6, USA. The natural frequency of the fundamental bending mode was measured and the corresponding bending stiffness was evaluated for each of bars. If the bar is macroscopically homogeneous, its bending stiffness reduces to the product $E I$, where $E$ is the effective Young's modulus of a material the bar is made of and $I$ is the area moment of inertia of the bar cross section. If the bar is macroscopically heterogeneous, the bending stiffness is connected with material properties and geometric characteristics in a more complex way.

To simulate conditions similar to human body, Hank's solution was used $(8 \mathrm{~g} / \mathrm{l}$ $\mathrm{NaCl}, 1 \mathrm{~g} / 1$ Glucose, $0.6 \mathrm{~g} / \mathrm{KH}_{2} \mathrm{PO}_{4}, 0.4 \mathrm{~g} / 1 \mathrm{KCl}, 0.35 \mathrm{~g} / 1 \mathrm{NaHCO}_{3}, 0.14 \mathrm{~g} / 1 \mathrm{CaCl}_{2}, 0.1 \mathrm{~g} / 1$ $\mathrm{MgCl}_{2} 6 \mathrm{H}_{2} \mathrm{O}, 0.06 \mathrm{~g} / 1 \mathrm{MgSO}_{4} 7 \mathrm{H}_{2} \mathrm{O}$, and $0.06 \mathrm{~g} / 1 \mathrm{NaH}_{2} \mathrm{PO}_{4} 2 \mathrm{H}_{2} \mathrm{O}$, with a $\mathrm{pH}$ value of 7.4). To assess their corrosion performance, samples were kept immersed in Hank's solution for 8 weeks at $37^{\circ} \mathrm{C}$. After this period, bars were taken out of the solution, cleaned in the 
ultrasonic bath (distilled water, ethanol) and dried. The bending stiffness of each bar was measured again.

\section{RESULTS AND DISCUSSION}

During sintering, manganese sublimed from Mn particles. Released vapour expanded into all accessible voids, which enabled vapour-deposition of manganese onto almost whole surface of iron particles. Once deposited, manganese atoms began to diffuse into Fe particles forming thus substitutional random $\mathrm{Fe}-\mathrm{Mn}$ alloys.

The diffusion of manganese atoms "from the outside" into iron particles "blew up" these particles. The expansion of Fe particles and the appearance of voids at positions of original $\mathrm{Mn}$ particles caused the porosity of specimens to increase with increasing $\mathrm{Mn}$ content. Densification by repressing and resintering has resulted in a lower porosity of samples pressed and sintered twice in comparison with the porosity of ordinary samples pressed and sintered once, (Tab.1.).

Tab. 1. Porosity of sintered Fe-Mn alloys.

\begin{tabular}{|l|c|c|c|}
\hline \multirow{2}{*}{ Composition } & \multicolumn{3}{|c|}{ Porosity [\%] } \\
\cline { 2 - 4 } & $\begin{array}{c}\text { Samples pressed } \\
\text { and sintered once }\end{array}$ & $\begin{array}{c}\text { Samples pressed, } \\
\text { sintered and } \\
\text { repressed }\end{array}$ & $\begin{array}{c}\text { Samples pressed } \\
\text { and sintered twice }\end{array}$ \\
\hline $\mathrm{Fe}$ & 17.1 & 5.5 & 6.2 \\
\hline $\mathrm{Fe}-25 \mathrm{Mn}$ & 28.4 & 17.6 & 17.8 \\
\hline $\mathrm{Fe}-30 \mathrm{Mn}$ & 28.5 & 20.1 & 20.3 \\
\hline $\mathrm{Fe}-35 \mathrm{Mn}$ & 31.9 & 20.5 & 20.5 \\
\hline
\end{tabular}

Taking into account the peak temperature and a hold time at this temperature, a mean displacement of a manganese from the surface towards the centre of an iron particle was estimated to be about $3 \mu \mathrm{m}$ [8]. Typical water-atomized iron particles were several teens of microns in diameter. Formerly homogeneous iron particles where therefore transformed into ones with an onion-like structure, with Mn-rich outer layers and Mn-poor particle cores [8].

After usual (not quasistatic) cooling from a temperature well above $912^{\circ} \mathrm{C}$ to the room temperature, Fe-Mn alloys may exhibit quite complex microstructures. Alloys with Mn contents up to $11 \mathrm{wt} \%$ represent substitutional solid solutions in which iron and manganese ions occupy at random regular sites of a body-centered cubic (BCC) lattice and exhibit microstructures consisting of domains of ferrite (unsaturated or saturated solid solution of $\mathrm{Mn}$ in $\mathrm{Fe}$ ) and/or $\alpha^{\prime}$-martensite (supersaturated solid solution). For Mn contents over 28 wt.\% (but lower than about 55 wt.\%), iron-manganese alloys show only an austenite phase in which iron and manganese ions occupy at random regular sites of a facecentered cubic (FCC) lattice. Fe-Mn alloys containing from 11 to $28 \mathrm{wt}$ \% of Mn exhibit complex microstructures consisting of domains in which iron and manganese ions occupy at random regular sites of a body-centered cubic lattice ( $\alpha^{\prime}$-martensite), hexagonal close packed lattice ( $\varepsilon$-martenzite), and face-centered cubic lattice (austenite) $[1,11,12]$.

After first sintering, previously ferritic iron particles were covered with an austenitic shell while their cores were still fully ferritic in the sense that the cores possessed the BCC structure. Between austenitic shells and ferritic/martensitic cores, there were layers with a fine-grain structure (Fig.1.). The concentration of $\mathrm{Mn}$ increased from the particle core towards the particle periphery. The EDX analysis also revealed the presence of 
oxygen (Fig.2.). This implied a considerable oxidation of samples during their processing, even when a high-purity sintering atmosphere was applied. A possible cause of this oxidation was a high affinity of manganese for oxygen, which enabled manganese to draw out an oxygen from a water molecule. Water molecules were present as a trace water vapour in the real sintering atmosphere $[13,14]$.

Free manganese was observed along particle boundaries. Residues of original manganese particles have formed agglomerates (Fig.2.) and, as the SEM+EDX analyses showed, they were composed of manganese, various manganese oxides, and a small amount of manganese sulphide.
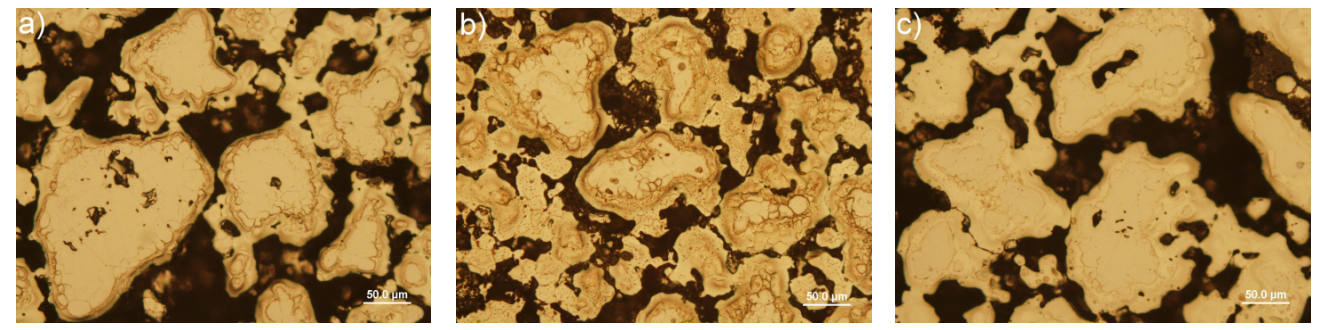

Fig.1. Optical micrographs of polished and etched sections through the interior of once pressed and sintered Fe-25wt.\% (a), Fe-30\%Mn (b), Fe-35\%Mn (c) samples.

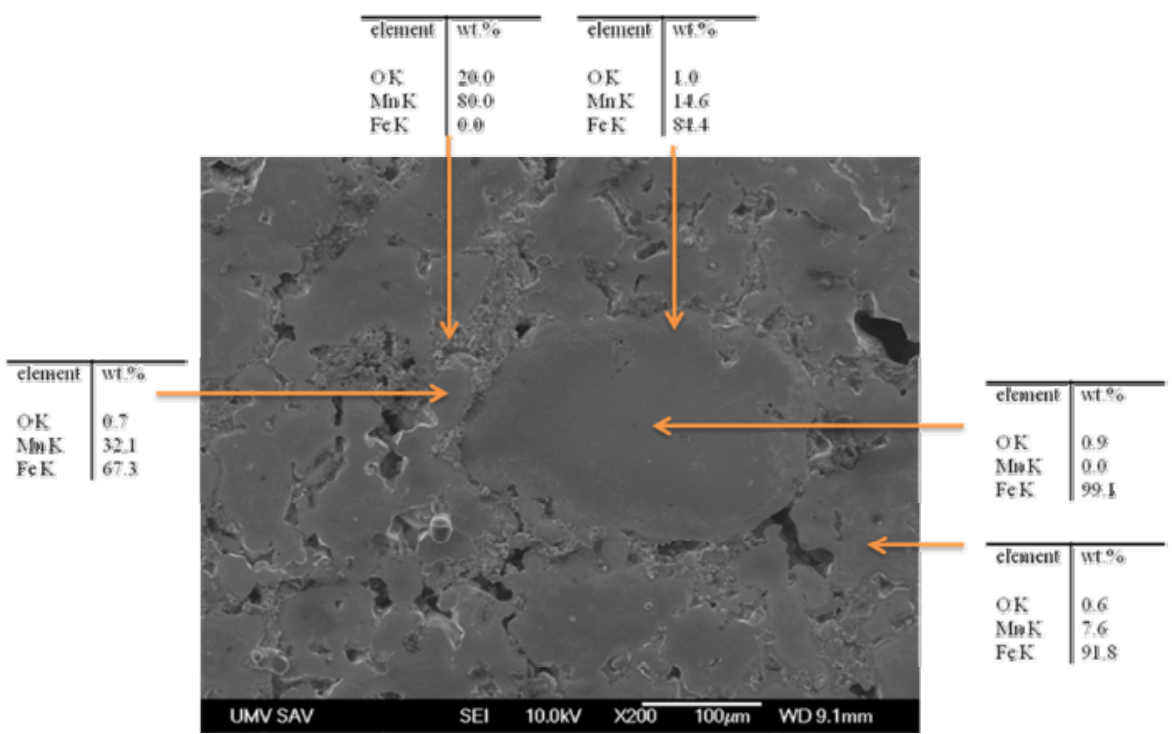

Fig.2. A SEM micrograph of a polished section of Fe-30wt.\%Mn sample pressed and sintered once, and the EDX analysis in different points of surface. 

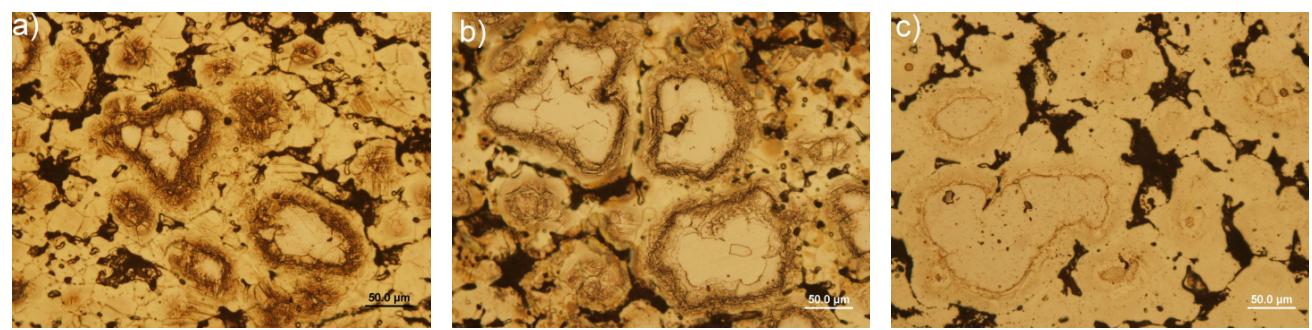

Fig.3. Optical micrographs of polished and etched sections through the interior of twice pressed and sintered Fe-25wt.\%, Fe-30\%Mn, Fe-35\%Mn samples.

During the first pressing and sintering cycle, the shell of oxides was created on the surface of Mn particles. This shell reduced the source of Mn and decelerated the process of diffusion alloying of Fe matrix.

During repressing, the shells of oxides were broken and the source of Mn was thus renovated. So, during resintering the process of diffusion homogenisation of distribution of Mn within Fe matrix continued.

In all Fe-Mn samples which were pressed and sintered twice, non-negligible amount of manganese penetrated practically all regions of iron particles, except for the central areas of the largest iron particles (about $100 \mu \mathrm{m}$ ) where the $\alpha$-ferrite was still present. After the second pressing and sintering cycle, the ratio of austenite to ferrite and martensite increased (Figures 3,4). The surface FCC layers of particles were thicker.

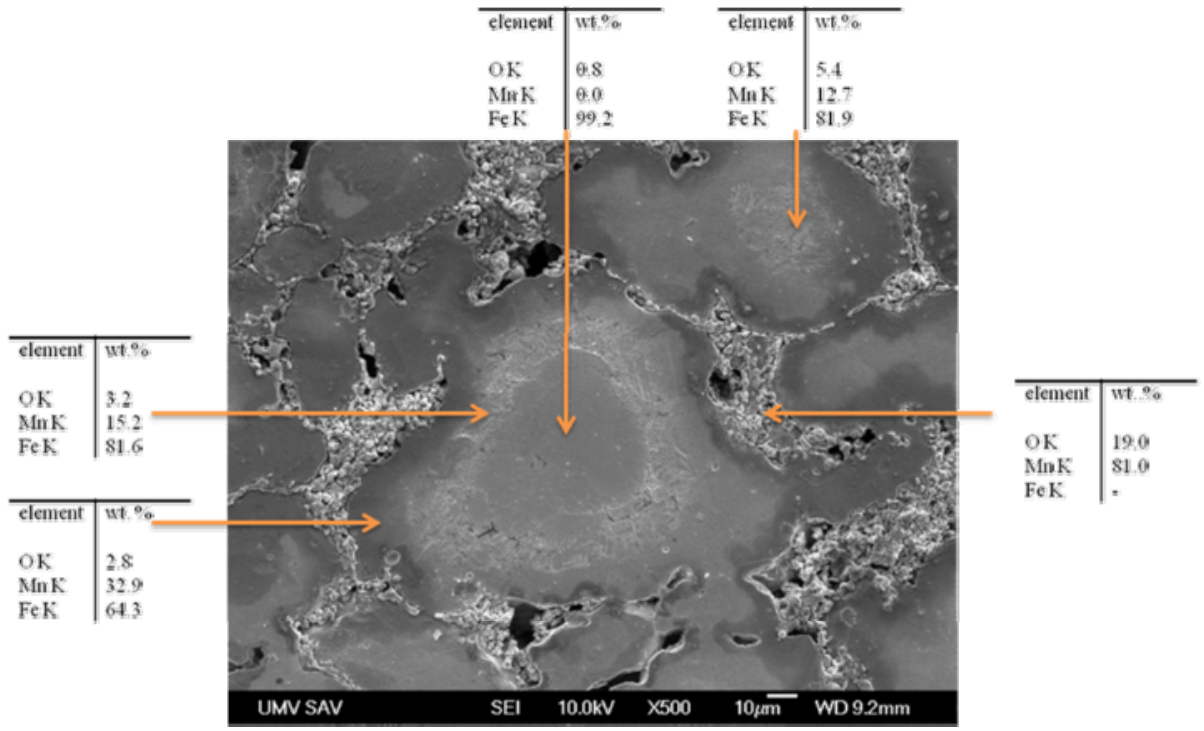

Fig.4. A SEM micrograph of a polished section of Fe-30wt.\%Mn sample pressed and sintered twice, and the EDX analysis EDX analysis in different points of surface.

The character of material's microstructure reveals itself, among others, in the distribution of Vickers microhardness values over the sample's cross section. The more homogeneous the material is, the more probable it is to find the same microhardness value at different points of sample. 
To investigate the distribution of microhardness values, 300 micro-indents were performed at different points of cross-sectional plane of each sample with the indentation loading of $10 \mathrm{~g}$, and the obtained microhardness values were recorded. Subsequently, the hardness range was divided into equal subranges, and the number of times a value from a given subrange occurred in the data set was evaluated for each of the subranges.
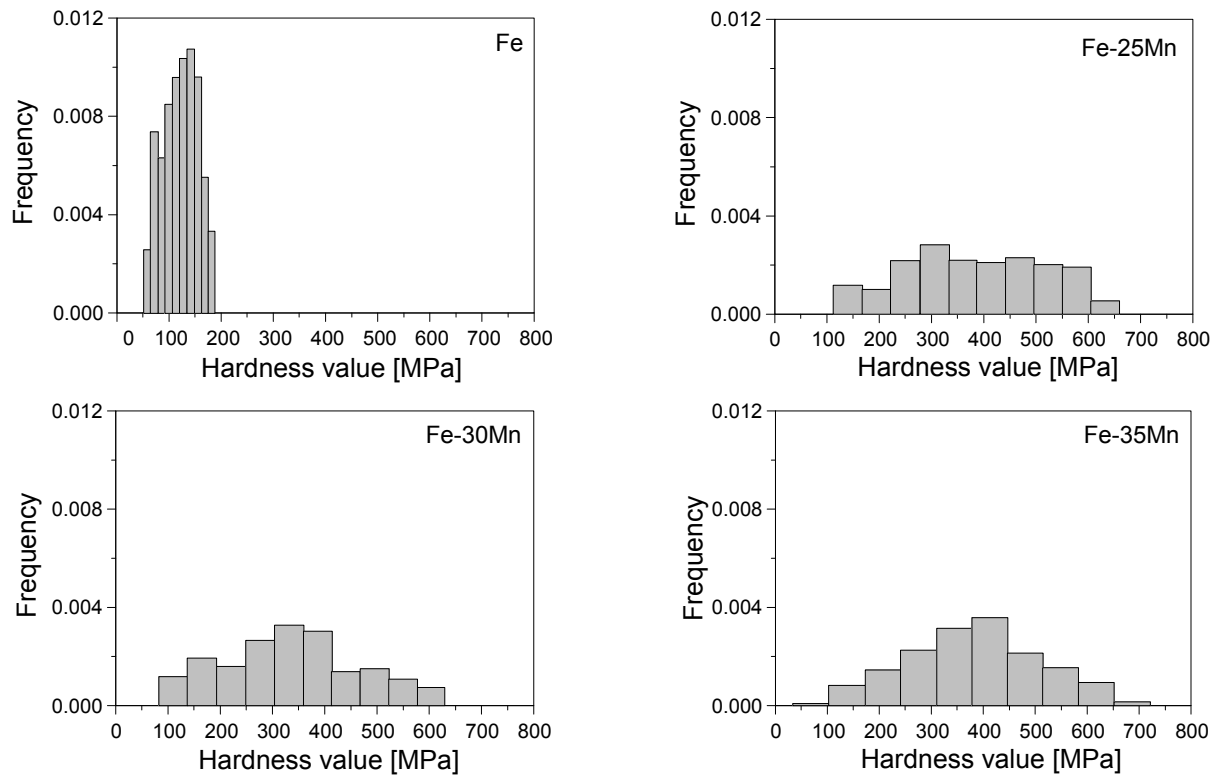

Fig.5. The relative number of times (frequency) a value from a given subrange of microhardness HV 0.01 occurred in the data set obtained for pressed and sintered samples from pure iron, Fe-25wt.\%Mn, Fe-30wt.\%Mn and Fe-35wt.\%Mn.

For the samples from a pure iron, observed microhardness values ranged from 50 $\mathrm{MPa}$ to $200 \mathrm{MPa}$ and the number of occurrences revealed a clear peak for the hardness value of $146 \mathrm{MPa}$ (Fig.5.). A low dispersion of measured values was a consequence of relatively homogeneous composition and uniform microstructure of samples. For samples from mixed powders pressed and sintered once, the measured microhardness values ranged from $50 \mathrm{MPa}$ to $700 \mathrm{MPa}$. This scattering of values was a consequence of spatially varying solid solution strengthening and transformation hardening, which varied from point to point due to gradients in Mn concentration. For Fe-25Mn samples, the numbers of occurrences of various hardness values were almost equal, without any clear extreme (Fig.5.). For Fe30Mn samples, an indication of a peak emerged for the hardness between $300 \mathrm{MPa}$ and 400 $\mathrm{MPa}$, and for Fe-35Mn samples there was clearly most frequently occurring hardness value of about $380 \mathrm{MPa}$ (Fig.5.). This was caused by the fact that as the amount of Mn dissolved in the sample increased, still larger volume of the iron particle was notably and quite uniformly alloyed with $\mathrm{Mn}$, that is, the microstructure and material properties have tended to become more uniform.

For Fe-Mn samples pressed and sintered twice, the range of measured microhardness values remained almost the same, but the numbers of occurrences of particular values changed (Fig.6.). This was connected with the increasing homogeneity in chemical composition and with decreasing number of domains consisting of various phases. 
While ordinary Fe-25Mn samples revealed more or less equal numbers of occurrences of various microhardness values, the microhardness values about $400 \mathrm{MPa}$ occurred clearly most frequently for repressed and resintered Fe-25Mn samples. For Fe-30Mn samples, the indication of maximal numbers of occurrences for microhardness values from 300 to 400 $\mathrm{MPa}$ became more pronounced. For Fe-35Mn material, the maximum number of occurrences shifted from hardness of $380 \mathrm{MPa}$ for ordinary samples to about $260 \mathrm{MPa}$ for repressed and resintered samples, which implied that the material, which was already quite homogeneous, remained homogeneous but became softer.
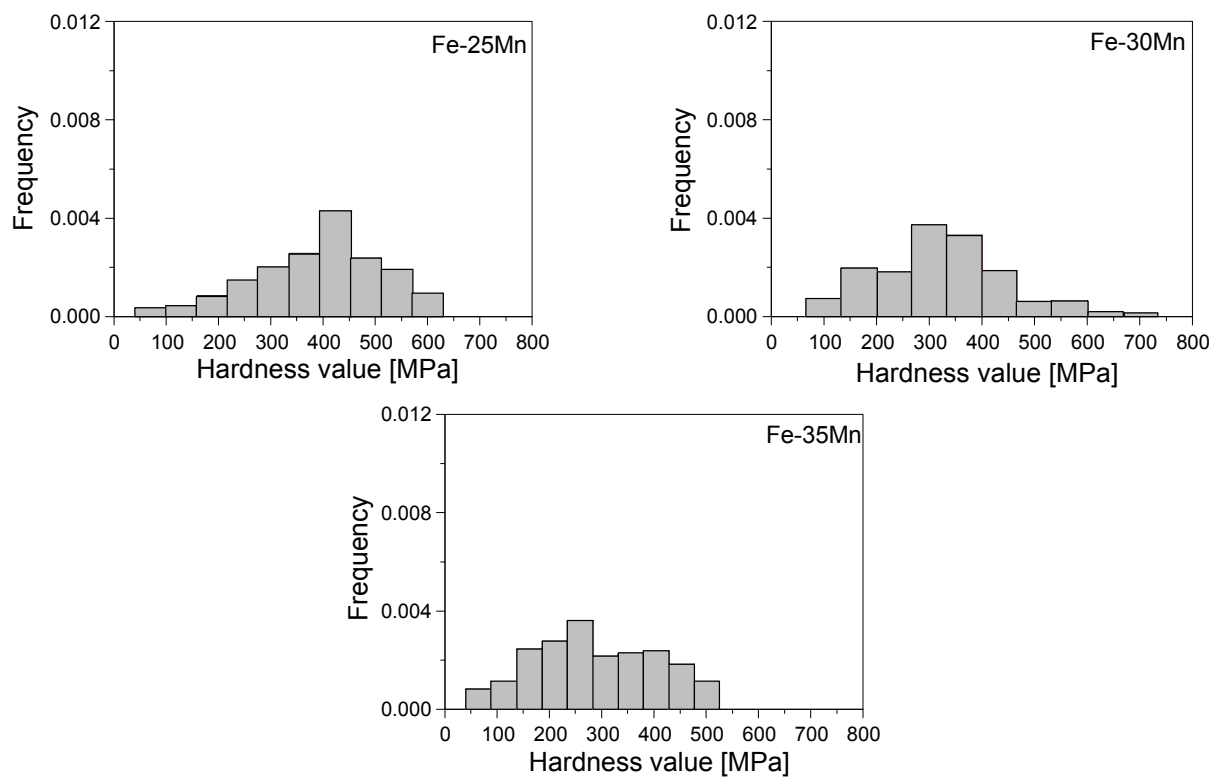

Fig.6. The relative number of times (frequency) a value from a given subrange of microhardness HV 0.01 occurred in the data set obtained for twice pressed and sintered samples from Fe-25wt.\%Mn, Fe-30wt.\%Mn and Fe-35wt.\%Mn.

Metallographic examinations and measurements of microhardness at different points of sample revealed that obtained sintered materials were inhomogeneous, their properties varied significantly from point to point within a micro-length scale. But for practical purposes, the significant material's behaviour is that which manifests itself on "human" length scales, i.e. scales which are large in comparison with any microstructure. In this context, it is usual to assume that the macroscopic elastic response of a real material is the response given by an equivalent homogeneous continuum with an effective Young's modulus $E_{\text {eff. }}$.

Properties of a sintered material are controlled by its porosity (or relative density) and by properties of its solid skeleton. The effective Young's modulus of a macroscopically homogeneous sintered iron-based material scales with its porosity as [15]

$$
E_{\text {eff }}=E_{0}(1-P)^{3.4} \text {. }
$$

Here $P$ is the porosity (void volume fraction) of sintered material and $E_{0}$ is the effective Young's modulus of a poreless (fully dense) material. 
Allowing for that the solid skeletons of our samples were in general comprised of various phases, the elastic modulus of a poreless material itself was most likely an effective modulus and could be expressed as [16]

$$
\left(E_{0}\right)^{n}=\sum_{i} v_{i}\left(E_{0 i}\right)^{n} \text {. }
$$

Here $n$ is a number between -1 (Reuss estimate) and +1 (Voight estimate), $E_{0 \mathrm{i}}$ are elastic moduli of particular phases and $v_{\mathrm{i}}$ are volume fractions of those phases, where $v_{1}+v_{2}+\ldots+v_{\mathrm{k}}=1$.

Regarding the elastic moduli of particular phases: Relying on measurements and first-principle calculations, the Young's modulus of 202.1 GPa for a BCC and that of 228.3 GPa for a FCC iron have been reported [17]. Dissolving Mn in the FCC iron has practically no effect on the modulus of FCC solid solution, i.e. the modulus of austenitic Fe-Mn alloys is independent on Mn content and equals the modulus of $\gamma$-iron. The stiffness of ferritic Fe$\mathrm{Mn}$ alloys slightly decreases as Mn content increases, and for about $10 \mathrm{wt} . \%$ of $\mathrm{Mn}$ the modulus is reduced by about $5 \%$ [18]. So, it can be expected that the elastic properties of skeleton material depend on the Mn content only very slightly.

The effect of manganese content on Young's moduli of samples prepared in various ways is demonstrated in Figure 7. This figure also shows the porosities of corresponding samples.
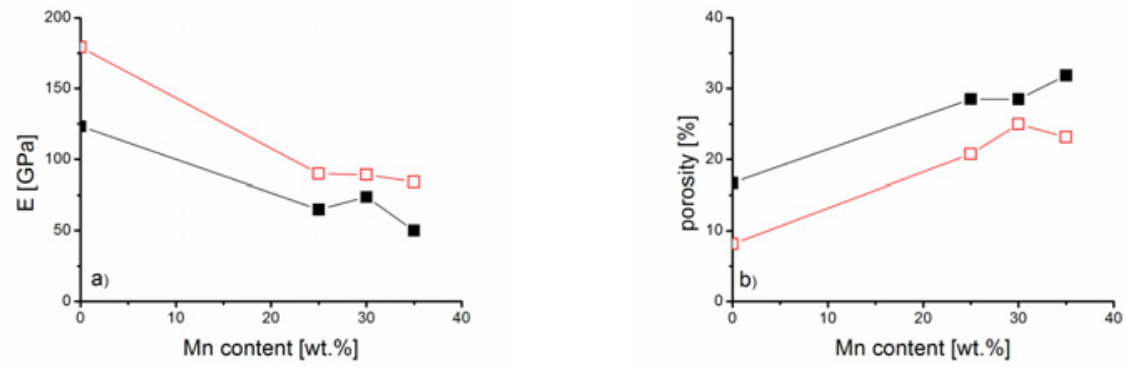

Fig.7. Young's modulus (on the left) and porosity (on the right) as functions of manganese content for samples pressed and sintered once $(\mathbf{\square})$, and twice $(\square)$.

The presented data indicate that the parameter which primarily controlled the Young's modulus value was the porosity of investigated materials. Slightly different moduli of materials with almost equal porosities, such as moduli of ordinary Fe-25Mn and Fe$30 \mathrm{Mn}$ materials, can be attributed to microstructures containing different volume fractions of ferrite and austenite [8].

The dominant influence of porosity (or relative density) on the effective Young's modulus is demonstrated in Figure 8. This figure shows the effective Young's modulus plotted against relative density for the investigated samples, irrespective of their chemical composition.

To examine the effect of corrosion on stiffness of materials, test bars were immersed in Hank's solution. After eight weeks, the bars were taken out of the solution, ultrasonically cleaned in distilled water and ethanol, and dried. The bending stiffness, $B$, of each bar was measured again and the ratio $B / I$ was evaluated. This ratio reduces to the effective Young's modulus for macroscopically homogeneous bars, and it is treated as the apparent modulus otherwise. 


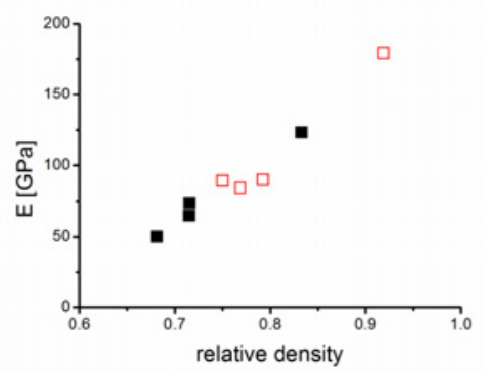

Fig.8. The effective Young's modulus as a function of sample's relative density. The Fe-Mn samples of various composition were pressed and sintered once ( $\square$ ) and twice ( $\square$ ).

Figure 9 presents results obtained for bars pressed, sintered and repressed (without second sintering). Practically no differences were observed between bending stiffness of bars before and after eight weeks of immersion in Hank's solution. On the other hand, Figure 10 presents results obtained for bars pressed and sintered twice. In this case, there were visible differences between bending stiffness of bars before and after immersion.

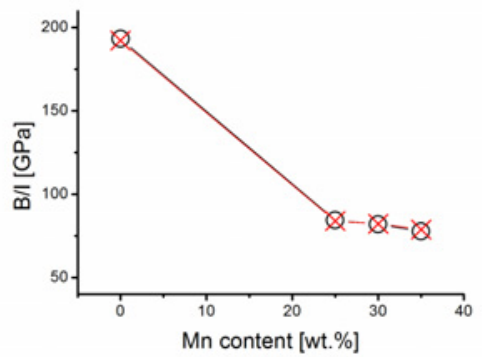

Fig.9. Apparent modulus $B / I$ obtained for bars from Fe-Mn alloys pressed, sintered and repressed. Empty circles are for as-sintered specimens, crosses for specimens exposed to Hank's solution.
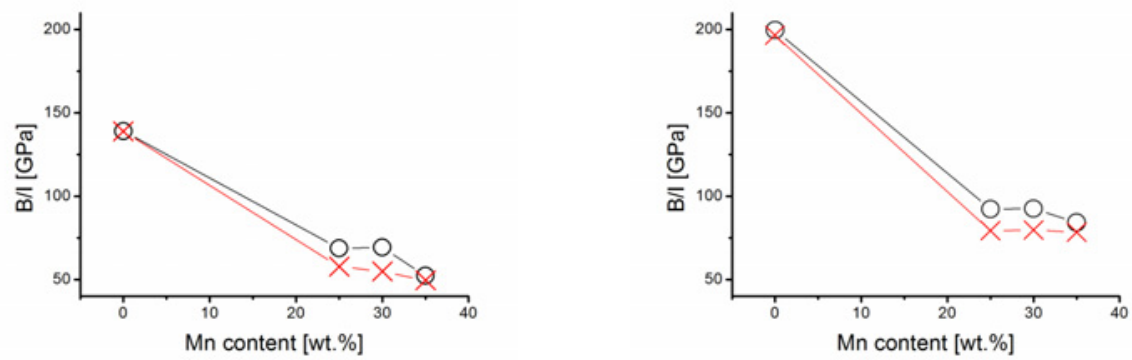

Fig.10. Apparent modulus $B / I$ obtained for bars from Fe-Mn alloys pressed and sintered once (on the left) and twice (on the right). Empty circles are for as-sintered specimens, crosses for specimens exposed to Hank's solution.

The porosities of bars pressed, sintered, repressed and bars pressed and sintered twice are practically the same (Tab.1.). But repressing deformed surface of bars and could close the connection between subsurface clusters of interconnected pores and free surface. 
Corrosion then removed only atoms from outer surface and did not change macrohomogeneity and material properties of the rest of sample. Resintering renewed the connection between subsurface clusters of pores and the free surface. When these clusters of pores were accessible from the surface, the electrolyte filled them and a long-term interaction with Hank's solution has transformed formerly macroscopically homogeneous bars into more or less "composite" ones with prismatic not damaged cores and shells comprised of a material affected by corrosion (Fig.11.). For such a "composite" bar, the bending stiffness no longer reduces to the product of "material" and "geometric" parts, it depends on effective moduli of both core and shell materials in a more complex way [19]

$$
B=I\left[E_{\text {core }}-\left(1-v_{\text {core }}^{2}\right)\left(E_{\text {core }}-E_{\text {shell }}\right)\right] \text {. }
$$

Here $v_{\text {core }}$ is the volume fraction of a not damaged core material. Note that if the volume fraction of damaged material is negligible or it is missing at all, $v_{\text {core }} \approx 1$ and $B=I E_{\text {core. }}$.

Corrosive attack can mechanically weaken the bar. If the interaction with an environment raises the compliance of a material near surface, $E_{\text {shell }}<E_{\text {core }}$, the bar becomes more prone to bending, that is $B / I<E_{\text {core }}$.

Figure 10 demonstrates that the eight-week immersion in Hank's solution affected the surface regions of Fe-Mn samples pressed and sintered both once and twice. Experimental results showed that bars exposed to Hank's solution possessed lower bending stiffness than geometrically equivalent not exposed bars (Fig.10.). So, the exposed bars consisted of stiff cores covered with floppy shells. This indicates that the interaction with Hank's solution lowered the stiffness of sintered Fe-Mn alloys themselves.

The detrimental effect of porosity on the corrosion resistance of sintered metals is rooted in an additional, quite "rugged" surface provided by the walls of surface-connected clusters of interconnected pores, surface, the area of which is usually about two orders of magnitude larger than the area of exterior geometric surface of a sample. The effect of surface-connected clusters of pores is demonstrated by the difference between Figures 9 and 10 .

In the simplest case, this large area of pore walls can be subject to uniform corrosion. Considering a material with a moderate porosity, with the solid skeleton undergoing uniform corrosion at a rate no higher than a few hundreds of microns per year, and using Eq. 3 and Eq. 1, the following relation for the rate of reduction of the bending stiffness (Eq.3.) can be found

$$
-\frac{1}{B} \frac{d B}{d t} \propto \frac{S R_{\mathrm{corr}}}{(1-P) \sqrt{A}} .
$$

Here $S$ is the real surface area per unit exterior-geometric-surface area of the sintered sample, $R_{\text {corr }}$ is the corrosion rate of the solid skeleton and $A$ is the cross-sectional area of the bar.

According to Eq.4., larger specific surface area accessible to electrolyte, higher porosity and less noble solid skeleton accelerate the reduction of bending stiffness of a bar. This in principle agrees with results obtained for sintered Fe-Mn materials, though the results were most likely affected by a galvanic interaction between ferritic and austenitic regions of the solid skeleton, which caused a not uniform corrosion of the skeleton material itself [8]. 


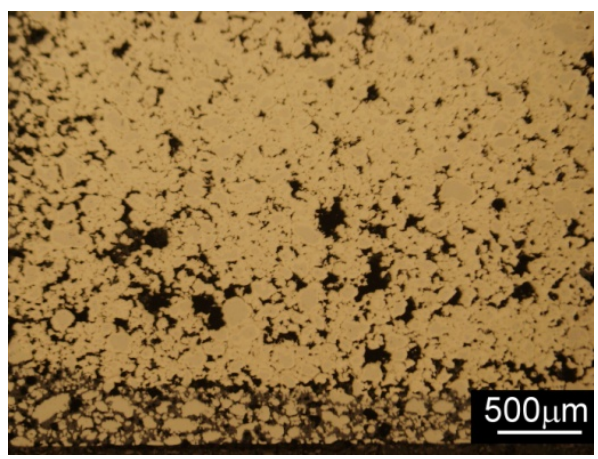

Fig.11. Optical micrograph of a section of Fe-30Mn sample after 8 week immersion in Hank's solution.

\section{CONCLUSIONS}

Iron - manganese alloys are promising degradable biomaterials for temporary load-bearing medical implants or fixation devices. When these alloys are produced by powder metallurgy, their characteristics are primarily determined by volume fraction of a void space (i.e. porosity), and by physical and chemical properties of solid skeleton materials.

To obtain materials with a wider spectrum of properties, some of ordinary pressed and sintered samples were repressed and resintered. The properties of Fe-Mn materials pressed and sintered once and twice were compared.

Samples pressed and sintered twice were found less porous, more stiffer, and possessing more homogeneous chemical composition and phase structure than samples with the Mn content but pressed and sintered once.

When the bars were exposed to a corrosive environment for a long time, the bending stiffness of bars pressed and sintered once and twice deteriorated similarly. Electrolyte filled clusters of overlapping pores connected to the bar surface, reactions between electrolyte and pore walls removed matter from these walls, and so the surface layer "penetrated" by the electrolyte weakened.

The fact that the clusters of interconnected pores accessible to electrolyte are important for deterioration of mechanical properties was demonstrated when the access of an electrolyte to those clusters was blocked by compressing the entrance mouths of cluster. The bending stiffness of bars pressed, sintered and repressed (but not resintered) was the same before and after eight weeks of immersion in Hank's solution, that is, those materials were not practically influenced by the exposure to corrosive environment. On the other hand, comparatively porous materials but pressed and sintered twice were influenced quite significantly.

Detailed investigation of relations between character of porosity, ability of electrolyte to fill the void space and degradation of mechanical properties represents the subject of further studies.

\section{Acknowledgement}

The authors thank for financial support of the research by the Slovak Research and Development Agency under contract APVV No. 0029-16, APVV No. 0677-11, VEGA grant 2/0100/15 and Slovak-Poland Project (SAV/PAV) No.22. 


\section{REFERENCES}

[1] Hermawan, H., Dubé, D., Mantovani, D.: Acta Biomaterialia , vol. 6, 2010, p. 1693

[2] Moravej, M., Purnama, A., Fiset, M., Couet, J., Mantovani, D.: Acta Biomaterialia, vol. 6, 2010, p. 1843

[3] Xu, Z., Hodgson, MA., Cao, PA.: Materials Science and Engineering: A, vol. 630, 2015, p. 116

[4] Hermawan, H.: Biodegradable Metals. From Concept to Application. Heidelberg : Springer, 2012

[5] Wegener, B., Sievers, B., Utzschneider, S., Müller, P., Jansson, V., Rößler, S., Nies, B., Stephani, G., Kieback, B., Quadbeck, P.: Materials Science and Engineering: B, vol. 176, 2011, p. 1789

[6] Witte, F.: Acta Biomaterialia, vol. 6, 2010, p. 1680

[7] Xu, Z., Hodgson, MA., Cao, P.: Metals, vol. 6, 2016, p. 309

[8] Kupková, M., Hrubovčáková, M., Kupka, M., Oriňaková, R., Morovská Turoňová, A.: International Journal of Electrochemical Science, vol. 10, 2015, p. 9256

[9] Kupková, M., Hrubovčáková, M., Zeleňák, A., Sulowski, M., Cias, A., Oriňáková, R., Morovská Turoňová, A., Žáková, K., Kupka, M.: Arch. Metall. Mater., vol. 60, 2015, p. 639

[10] Kupková, M., Hrubovčáková, M., Kupka, M.: Mater. Sci. Forum, vol. 844, 2016, p. 46

[11] Peng, Q., Song, Ch., Xia, W., Zhai, Q. In: TMS 2013 Annual Meeting Supplemental Proceedings. New Jersey : John Wiley \& Sons, 2013, p. 869

[12] Lee, YK., Jun, JH., Choi, CS.: ISIJ Int., vol. 37, 1997, p. 1023

[13] Danninger, H., Gierl, C.: Science of Sintering, vol. 40, 2008, p. 33

[14] Hryha, E., Dudrová, E., Nyborg, L.: Metallurgical and Materials Transactions A: Physical Metallurgy and Materials Science, vol. 41, 2010, p. 2880

[15] German, RM.: Sintering: From Empirical Observations to Scientific Principles. Oxford: Elsevier Butterworth-Heinemann, 2014

[16] Soboyejo, W.: Mechanical Properties of Engineered Materials. New York : Marcel Dekker, 2003

[17] Su, D., He, YL., Liu, JQ., Lu, XG. In: $1^{\text {st }}$ Int. Conference on Information Science, Machinery, Materials and Energy. Eds. X. Ching, V. Dvorik. Chongquing : Atlantis Press, Curran Associates, Inc, 2015, p. 1840

[18] Hosford, WF.: Iron and Steel. New York : Cambridge University Press, 2012

[19] Kupková, M., Kupka, M., Strobl, S., Černý, M., Khatibi, G., Gierl, C.: Scripta Materialia, vol. 57, 2007, p. 639 